Aletria, Belo Horizonte, v. 30, n. 1, p. 189-203, 2020

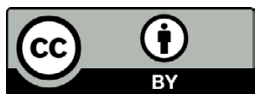

\title{
Superastro: um dispositivo de observação e reflexão teórica da performance?
}

\author{
Superstar: A Device of Observation \\ and Theoretical Reflection of Performance?
}

\author{
Aline Magalhães Pinto \\ Universidade Federal de Minas Gerais (UFMG), Belo Horizonte, Minas Gerais / Brasil \\ alinealinemp@gmail.com \\ http://orcid.org/0000-0003-0164-0061
}

Resumo: O texto busca considerar criticamente a noção de superastro, presente no livro Uma Literatura nos Trópicos, de Silviano Santiago (1972), entendendo-a como um operador interpretativo que pode tornar possível um exercício de teorização no horizonte conceitual e fenomênico aberto pela performatividade e pelo modo temporal que a perpassa: a presença. A questão levantada é se a exuberante figura do superastro pode servir como dispositivo de observação e reflexão teórica da performance.

Palavras-chave: performance; superastro; Silviano Santiago; presença; teoria da literatura.

Abstract: The text seeks to critically address the notion of superstar, present in the book A Literature in the Tropics by Silviano Santiago (1972), understanding it as an interpretative operator that can become an exercise of theorizing on the conceptual and phenomenal horizon opened by performativity and by the temporal mode that runs through it: the presence. The question is whether the lush figure of the superstar can serve as a device for observation and theoretical reflection of performance.

Keywords: performance; superstar; Silviano Santiago; presence; theory of literature. 
Toda essa gente se engana

Ou então finge que não vê que eu nasci

Pra ser o superbacana

Eu nasci pra ser o superbacana

Superbacana Superbacana

Superbacana Super-homem

Superflit, Supervinc

Superist, Superbacana

Estilhaços sobre Copacabana

O mundo em Copacabana

Tudo em Copacabana Copacabana

O mundo explode longe, muito longe

O sol responde

O tempo esconde

$\mathrm{O}$ vento espalha

$\mathrm{E}$ as migalhas caem todas sobre

Copacabana me engana

Esconde o superamendoim

$\mathrm{O}$ espinafre, o biotônico

O comando do avião supersônico

Do parque eletrônico

Do poder atômico

Do avanço econômico

A moeda número um do Tio Patinhas não é minha

Um batalhão de cowboys

Barra a entrada da legião dos super-heróis

E eu superbacana

Vou sonhando até explodir colorido

No sol, nos cinco sentidos

Nada no bolso ou nas mãos

Um instante, maestro

Super-homem Superflit

Supervinc, Superist

Superviva, Supershell

Superquentão

(Caetano Veloso, Superbacana, 1967)

O superastro é superbacana. E "superflit, supervinc, superist, superviva, supershell, superquentão". (VELOSO, 1967) Esse texto visa, em forma ensaística, responder à oportunidade ${ }^{1}$ de explorar $o$ potencial desse superlativo. Isso é, nas linhas que se seguem, me arrisco

\footnotetext{
${ }^{1}$ Ensejo que teve lugar no dia 13 de setembro de 2018, por ocasião do Seminário "Uma literatura nos trópicos 40 anos: dependência cultural e cosmopolitismo no pobre", organizado por André Botelho, Mariana Chaguri, Maurício Hoelz e Roberto Said e promovido pelo Núcleo de Estudos Comparados e Pensamento Social do PPGSA/IFCS/ UFRJ (NEPS - UFRJ/UFF), pelo Programa de Pós-graduação em Sociologia da Unicamp, pela Faculdade de Letras da UFMG e pela Biblioteca virtual do Pensamento Social.
} 
a mostrar como, no território aberto pela temática da performance/ performatividade - solo impossível de ser definido de forma geral e simples -, a elaboração teórica desenvolvida por Silviano Santiago, em Uma Literatura nos Trópicos, tem uma contribuição a fazer. Esse risco é, certamente abrandado porque não estou sozinha nessa aposta. Fazem-me companhia, evidentemente, toda uma literatura consolidada nas pesquisas sobre contracultura e tropicalismo ${ }^{2}$. Seguindo, então, por essa linha mais ou menos já traçada, o meu plano consiste em pensar essa contribuição de S. Santiago a partir da noção de Superastro sob o ponto de vista da reflexão teórica.

Em minha hipótese, não considero superastro como o sujeito de uma performance, o performista incarnado por excelência pelo ícone Caetano Veloso, maior representante da cultura jovem da época da publicação do artigo de Silviano Santiago. Gostaria de tomar o superastro como um refinado operador interpretativo que torna possível um exercício de teorização, inserido no horizonte conceitual e fenomênico aberto pela performance e pelo modo temporal que a perpassa: a presença. A questão que levanto, como uma via a ser pavimentada, é se a exuberante figura do superastro pode servir como dispositivo de observação e reflexão teórica.

Para construção dessa hipótese a referência central será, com nenhuma surpresa, o ensaio "Caetano Veloso enquanto Superastro". Esse texto, escrito em 1972, nos informa que:

1. "O superastro é o mesmo na tela e na vida real, no palco e na sala de jantar, na tv e na esquina, no disco e na praia" (SANTIAGO, 1978, p. 141);

2. "O superastro vive em toda sua plenitude e contradição comunitária os 365 dias de carnaval e da máscara alheia” (SANTIAGO, 1978, p. 141);

3. “O superastro é deus, é artista, é pessoa: é superior, é diferente, é semelhante. Tudo isso ao mesmo tempo" (SANTIAGO, 1978, p. 143);

${ }^{2}$ Sendo impossível um levantamento exaustivo, aponto, de relance, na produção relativamente recente, os textos de Flora Süssekind "Coro, contrários, massa: a experiência tropicalista e o Brasil de fins dos anos 1960", p. 31-58; Pássaro de fogo no terceiro mundo: O poeta Torquato Neto e sua época, de André Bueno, 2005; e Eu, brasileiro confesso minha culpa e meu pecado: cultura marginal no Brasil nas décadas de 1960 e 1970, de Frederico Coelho, 2010. 
4. "O superastro é também um estilo de vida" (SANTIAGO, 1978, p. 148), e finalmente,

5. "Ele funciona como um modelo" (SANTIAGO, 1978, p. 154)

Como o mesmo Caetano, ao redor do qual o ensaio sobre o Superastro gravita, nos incita a fazer em Elegia, canção do álbum Cinema Transcendental, solicito para pairar "atrás, na frente, em cima, em baixo, entre" (VELOSO, 1979) (d)o centro argumentativo expresso no ensaio, o caráter anfíbio do conjunto do pensamento teórico de Silviano Santiago. Entendemos, como caráter ou força ambígua, a potência de uma forma de pensar marcada por diversas zonas de descentramento, que vêm flagrar lances de heterogeneidade cultural simultâneos ao momento em que a civilização cientifica-tecnológica-industrial sufoca o que subsiste de outras culturas e impõe um modelo de uma brutal sociedade do consumo.

Gostaria, rapidamente, de evocar, como forma de apontar para o delineamento desse caráter ou força anfíbia do pensamento de Silviano Santiago, três momentos ou pontos, que funcionam, como se verá adiante, de alicerce para pensar a função teórica desempenhada pelo dispositivo superastro.

1. O primeiro momento é inescapável: o célebre ensaio "O entre-lugar do discurso latino-americano" (1978), com que Santiago abre Uma literatura dos trópicos fazendo emergir o operador ou conceito que se anuncia como locus de enunciação, espaço territorial, geográfico e discursivo: o entre-lugar. Por meio dele, Santiago afirma a especificidade da América Latina, instituindo seu lugar no mapa da tradição ou do patrimônio ocidental. O lugar latino-americano passa a ser, pela elaboração de Santiago, ligado ao movimento de desvio da norma, que transfigura os elementos que os europeus exportavam para o Novo Mundo. Sem o poder de se configurar como originalidade, mas também sem se fechar ao estrangeiro, o discurso latino americano se posiciona e extrai proventos desse entre-lugar. Das inúmeras implicações decorrentes desse procedimento, para a construção da minha hipótese, aponto o fato de que se apreende do entre-lugar um estar-sempre-em-trânsito, um modo ou maneira de ser-como-inquietante transitoriedade.

2. Como segundo momento, aponto $O$ cosmopolitismo do pobre, (2004) em que os ensaios retomam as questões culturais em função 
da disposição daquele que fala e daquele que ouve (recepção). Ao longo dos ensaios dessa obra, o autor constrói uma argumentação alternativa para as ideias de totalização, homogeneidade e exclusão. Ao enfatizar a massificação como inexorável processo ligado ao mundo da literatura, Santiago afirma sua condição de escritor de "uma Literatura Anfíbia" em um país onde o analfabetismo ainda assombra, através de uma irreverente interpretação do problema posto pela sociedade de massa. Para ele, o processo de alfabetização era considerado o caminho para a emancipação quando, no século XIX, e no começo do século XX, o acesso ao saber era realizado predominantemente pelo domínio da língua escrita, com o livro e o jornal diário. Com o desenvolvimento da cultura de massa e das tecnologias de informação e comunicação durante o século XX, mudaram tanto os valores que rodeiam a arte e a literatura, quanto a concepção do processo de alfabetização. $\mathrm{O}$ ato de leitura não mais está restrito ao livro e ao jornal. Ele diz respeito ao vídeo, à televisão, às possibilidades abertas pela internet. Em virtude disso, o sentido plural da produção cultural promove a desmontagem de um cosmopolitismo que previa regras de igualdade e de socialização, enquanto esse mesmo processo de codificação social produzia o aterramento das diversas formas culturais desviantes de tais regras. Ao produzir esse rearranjo de ideias, Santiago contribui para a elaboração de um novo multiculturalismo, em que não se deve buscar a homogeneização das partes, mas a convivência e o diálogo entre as diferenças. Esse território do comum e do compartilhado, em que o mesmo funciona como suporte do diferente é decisivo para que a função teórica do superastro possa vir a se cumprir.

3. O terceiro ponto está em Ora (direis) puxar conversa (2006), em que Santiago trabalha o rendimento crítico do entre-lugar como um dispositivo capaz de assinalar e desdobrar, em uma obra, os elementos que marcam sua subversão. Focalizando a questão a partir da literatura brasileira, Silviano Santiago afirma que para a forma cultural inscrita sob o nome "Brasil" poder se exteriorizar (sair-desi ou expressar-se) é antes preciso que ela acate (para-si) o exterior em toda a sua concretude. Nesse sentido, uma consciência nacional estará menos vinculada ao conhecimento de sua interioridade e mais centrada no complexo processo de interiorização do que lhe é exterior e estrangeiro. Caminhando nessa direção, e é o que é 
decisivo para minha hipótese, desabrocha um modo de aproximarse do outro: gesto que evita a primazia do sair-de-si ou negar-se (Hegel) e procura deixar-se penetrar como uma constante troca entre sujeito-objeto-sujeito. Esse modo de aproximação é uma aposta na força heteronômica da literatura e em sua possibilidade de fazer advir o outro enquanto uma potência singular e anônima. Interessa ao argumento aqui em construção, justamente, esse vir-aser, singular e anônimo e, por isso mesmo, potência e força plástica sem identidade.

Reunindo os três pontos, o desenho dessa força anfíbia emerge constituído pelo encadeamento entre:

1. o "entre-lugar" e sua consequência, um estar-sempre-em-trânsito;

2. uma concepção de cosmopolitismo que cria um terreno de reconhecimento entre diferenças e dissonâncias; e

3. uma configuração formal da consciência em que o processo de interiorização do que lhe é exterior e estrangeiro engendra uma potência anônima, impessoal, pública, ao pertencer a todos e a ninguém ao mesmo tempo.

Nesse ponto podemos então nos perguntar: O que será possível obter ao projetar, sobre o operador "Superastro", a força anfíbia entendida a partir do esquema que esbocei acima - do pensamento de Silviano Santiago?

Oposto ao astro que é submetido à diferença entre atuação e realidade, o Superastro é sempre o mesmo. A máscara e maquiagem perdem a função de acionar a distinção entre palco/tela e "vida real" para se converterem em acessórios. Esses acessórios possuem a função de índice e testemunho: não é a distância entre real e encenação que desapareceu. Essa distância perde sua dimensão de fronteira estática e aparece, com o superastro, como movimentação, como dinâmica. Os acessórios, extravagantes e espontâneos, nos fazem ver que o superastro, enquanto função teórica, está sempre em trânsito entre as dimensões do real e daquilo que o escapa. O superastro vai de um lado para o outro, sem à fronteira se submeter. Ele é a própria cinética entre polos não estáveis de um espaço em que ele, superastro, não conforma enquanto uma diferença, mas como possibilidade de reconhecimento das dissonâncias e ruídos entre palco/tela e "vida real". A possibilidade de reconhecer a 
diferença está sempre em aberto porque o superastro - sem precisar de uma identidade - não se parece com nada a não ser consigo mesmo. Para ser ele mesmo, muda o tempo inteiro. Em suas mutações, diferentes configurações tornam-se visíveis. Em outras palavras, por meio dele, superastro, a diferença se faz ver.

Silviano Santiago afirma, sobre o superastro, uma integração arte-vida, arte-cidade, arte-corpo. Tudo pode ser "vivido" como parte integrante desse "todo" porque, uma vez ativado o modo temporal da presença performática, entre o corpo do artista e o corpo do homem, emerge uma instância dele, da qual parte a diferença. "O espaço instaurado pelo superastro é o do mesmo" (SANTIAGO, 1978, p.141), nos diz Santiago. O assemelhar-se somente a si o tempo todo garante a esse movimento entre palco/tela e "vida real", o efeito de autenticidade do espetáculo cotidiano: como se a vida pudesse ser 365 dias de carnaval (SANTIAGO, 1978, p.141)

Mas, como as epígrafes do ensaio já advertem, para que essa possibilidade se sustente, é preciso que o superastro se travista e engane. Cative a todos pela insustentabilidade de seu percurso. O que exige a catalisação de todos elementos do mundo cotidiano lançados em direção à uma interioridade vazia (porque semelhante apenas a si mesmo).

Como interioridade vazia, sem identidade, o superastro é como se fosse corpo. Comporta-se como corpo em movimento. Isso é, uma configuração que, ao interiorizar o que lhe é exterior e estrangeiro, engendra a si mesmo como potência anônima e singular. O superastro não se apresenta como um meio que estende o corpo - ele suga o que está ao redor e oferece para essa dispersão um modelo, plástico e mutável: ele é proposta de modelagem para o cotidiano.

Nesse momento, é importante retomar um dos contextos ${ }^{3}$ em que a noção de superastro é formulada. No Brasil, desde a década de 1950, a

\footnotetext{
${ }^{3}$ Nos referimos a "um dos contextos", herdando as discussões já bastante amadurecidas vindas do campo da História dos Conceitos/ História Intelectual. Nesse sentido, sabemos que o alcance de um contexto nunca pode ser dissociado da análise do texto, e em função dela, todo contexto é transformador-transformável, exportador e exportável. Recortar o contexto de emergência da noção superastro é imediatamente corromper a pretensa pureza dele, pois exige que se engendre um limite contextual que por si só não estaria lá. Como afirmo em outra oportunidade, "esse limite se constitui como condição para que a transformação contextual permaneça sempre inacabada. Isso não supõe que os textos devam ser apartados de seus contextos, mas, pelo contrário, que
} 
expansão e aprofundamento da industrialização e a internacionalização dos mercados modificam significativamente o país, possibilitando o surgimento das práticas e fenômenos relacionados ao que se pode denominar como indústria cultural. ${ }^{4}$ Nesse sentido, uma política de adaptação aos padrões globalizados do mercado com táticas de vendagem e estratégias de ampliação de uma cultura de massas é parte constituinte da cena cultural brasileira nos anos 1960 e $1970 .{ }^{5}$ Nesse contexto, a performance desponta nas atividades cênicas, musicais e plásticas, compondo uma estética do precário, do transitório e do previsível para a qual Silviano Santiago, em "Bom Conselho" (ensaio do mesmo Uma Literatura nos trópicos), chama atenção e sugere, em relação a ela, que não qualificássemos os jovens de superficiais, tão apressadamente (SANTIAGO, 1978, p. 158). O operador textual superastro aparece, portanto, relacionado à tarefa crítica de, com paciência e deleite, superar a afobação das respostas rápidas e preconcebidas, sem que isso significasse subtrair a urgência da demanda por compreensão de fenômenos que desafiavam solenes distinções entre arte e produtos da indústria cultural.

só existem contextos sem nenhum centro absoluto de ancoragem" (xxxx. 2010) D. Lacapra, ao tratar das complexas relações que podem existir entre texto e contexto, formula seis tipos de contextos históricos possíveis. Sua preocupação é menos esgotar os tipos de contexto do que demonstrar o quanto a naturalização da ideia de contexto pode empobrecer a historiografia, sobretudo a história intelectual. Estendemos, por nossa conta, que desviar-se da relação entre texto e contexto limita a reflexão teórica que tem como objeto a literatura. Ele lista os seguintes contextos: relação entre intenção do autor e texto; relação entre vida do autor e texto; relação entre sociedade e texto; relação entre cultura e texto; relação entre texto e corpo da escrita; relação entre modos de discurso e texto. Cf. LACAPRA, 1983, p.36-71.

${ }^{4}$ Termo crítico que se tornou célebre após a publicação, em 1947, dos textos reunidos sob o nome de Dialética do Esclarecimento por T. Adorno e M. Horkheimer e designa os processos sociais envolvidos na progressiva expansão da lógica do capitalismo sobre o domínio do cultural, contemplando as relações simbólicas com (corpo), a natureza, as formas de interpenetração humanas e as esferas específicas de produção do conhecimento etc. Ciente das limitações inscritas no horizonte do conceito - especialmente devidas à plasticidade dos arranjos sociais e práticas culturais -, recorremos ao termo indústria cultural para indicar o processo contínuo de fornecimento de motivações para a produção de bens culturais cada vez mais homogêneos e autorreferentes constituído em suas partes em função de sua articulação total. Cf. MELLO, 1982.

${ }^{5}$ Para maior detalhamento da ampliação do mercado de bens culturais no Brasil, cf. ORTIZ, 1988. 
A respeito da performance, Paul Zumthor fornece uma instrução elementar: qualquer que seja a maneira pela qual somos levados a manejar a noção de performance encontraremos como elemento irredutível a ideia da presença de um corpo. Recorrer a ela implica, portanto, na necessidade de introduzir uma consideração sobre o corpo: em sua relação com o espaço que ele produz e ocupa, e em sua relação com a percepção e apreensão do tempo em que se desenrola sua atividade. A performance refere-se, temporal e espacialmente, à presença concreta dos participantes de uma ação de maneira imediata (ZUMTHOR, 2018, p. 47). Jacques Derrida também chama atenção para o fato de que a configuração performativa atua como um jogo de figuração entre nós mesmos e nossos mundos: algo que está lá apenas na ação, sustentada em ação e em movimento não cristalizável como factualidade / materialidade. $\mathrm{O}$ que acontece, como configuração performativa, não é uma "natureza" ou "substância", e sim, ciclos ou espirais de feedbacks em curso de ação-reação-interação. Uma performance faz aparecer a condicionalidade da ação, exatamente porque, para Derrida, como o mundo não é infinitamente maleável, ele oferece resistências que são ressignificadas, a cada performance. (DERRIDA, 1975)

O modo temporal da performance, a presença, enfatiza a experiência espacial e a lança em direção ao tempo, buscando afirmar a efemeridade do corpo contra a duração. É por estabelecer essa relação tensa e mesmo destrutiva entre espaço e tempo que a performance impõe repensar a questão da representação. A presença se faz tangível ao corpo, como uma série de atos performativos que atualizam as formas e esquemas culturais, mas desafia a fixação desse processo de atualização de virtualidades: a performance permanece um lugar vazio no processo de criação. Nesse ponto, discordamos das pesquisas que estabelecem, na esteira do trabalho fundamental de Victor Turner, uma necessária relação, na performance cultural, entre reciprocidade e reflexividade. ${ }^{6}$ Do ponto de vista que tomamos aqui, a performance

\footnotetext{
${ }^{6}$ Entre os anos 1950-1960, Victor Turner traz um novo ângulo aos estudos dos rituais ao tomar como foco os estados intermediários, suas ambiguidades, contradições e paradoxos sempre em relação aos sistemas simbólicos e aos sistemas de ação. A apreensão do ritual como instância de uma experiência em que a capacidade de criar e de transformar ganha uma forma na consciência dos sujeitos esteve presente, segundo Cavalcanti (2018), desde seus primeiros trabalhos. Mas, como aponta a mesma autora,
} 
permanece crucial, mas decisivamente inexplorável: resiste piamente a ser enunciada ou problematizada de forma reflexiva. Em sua asseveração da imediaticidade, a performance comunica e expande a presença do corpo, mas não garante sua reflexividade.

Fenômeno heterogêneo, as experiências performativas e performáticas ressoam em múltiplos campos ao trazer para o centro das atenções o problema do desempenho como instância de validação da prática, processo e experiência. Isso provoca inquietações epistêmicas desde as áreas dos estudos culturais, pós-coloniais (inclusos aí os estudos de gênero e etnia), a teoria crítica, história e teoria da artes, semiótica e iconografia, design e arquitetura até o mundo das corporações sociais e financeiras, das estratégias industriais, passando pelos campos jurídicos e políticos.

Nesse solo movediço, segundo a hipótese que levanto, encontra-se a funcionalidade teórica do superastro. Esse operador permite enfrentar o estado de imediata "empiricidade" (usando o termo de Zumthor) da noção de performance. Em outras palavras, o superastro permite teorizar a performance. Na fluidez da "curtição" - que para Santiago é índice da sensibilidade estética de uma geração -, o superastro atua como um agente de coagulação. No instante-instância da presença performática, o superastro não é amorfo ou inefável, irredutível a si mesmo. Ao contrário, ele dá a forma, configura plasticamente um modo de estar. O superastro é corpo presente, mas não apenas. Ele é corpo, voz, letra, dança, música direcionados, como um feixe de luz que, numa profusão de estímulos, indica um caminho. Imprime uma forma à dispersão. O superastro

o diálogo com o teatro experimental se torna mais intenso a partir da década de 1970, através do contato com o teatrólogo Richard Schechner. A partir de então, a obra do autor passa a tematizar de forma direta as conexões entre a performance ritual e teatro moderno, como mostram os ensaios de On the edge of the bush. Anthropology as experience (1985). Nesse trabalho, o autor se empenha em mostrar como as performances são, por excelência, expressões dos processos sociais que podem ser analisadas como (e por meio do conceito de) drama social. O drama social aparece como uma unidade espontânea da performance social humana abolindo a distinção entre fluxo e reflexão pois deixa-se reger por uma urgência acerca da causa e do motivo da ação performática. Aqui encontra-se nosso ponto de divergência: entendemos que o drama social não diluí a distância entre fluxo e reflexão, ao contrário, o fluxo das ações na performance permanece preso em sua imediaticidade. Cf. TURNER, 1985, 1987. CAVALCANTI, 2013. 
interpreta a performance, não apenas a executa em uma harmônica atuação. Santiago ilustra esse movimento ao diferir, no ensaio sobre o superastro e também em "Bom conselho", Caetano Veloso de Roberto Carlos. Enquanto o Rei trabalha em harmonia com o cafona, Caetano e também Gilberto Gil, - no cumprimento da função Superastro, marcam um limite. Com eles, "o cafona e a distância crítica se contradizem para poder o cantor comentar e ao mesmo tempo cantar o texto, isto é, dizer o texto ipsis litteris, distorcendo, no entanto, sua mensagem" (SANTIAGO, 1978, p. 165). O superastro não apenas se encontra na limiaridade, ele lança luz ao agônico conflito entre valores e significados inerentes a essa situação-limite.

A tarefa teórica cumprida pelo superastro consiste, portanto, em permitir ao espectador-crítico ouvir/ ver/ sentir o comentário distorcido implicado na performance. Se, em seu modo próprio - presa à imediaticidade e à presença, a performance tende a se esvair, como areia entre os dedos, o superastro atua como uma maleável peneira: instrumento que nos torna aptos a perceber, na singularidade de cada performance, a instância do mesmo. Essa instância não serve de plataforma para a encenação de elementos pretensamente universais. Ao contrário, ela lança um apelo silencioso e subterrâneo à agitação que compõe a performance, mostrando aquilo que, em cada iteração, é comum. Ou mais importante: se tornou comum e compartilhado, público.

A força anfíbia que sustenta a elaboração do operador superastro salvaguarda da feroz potência de diluição do modo temporal da presença, que tende a tudo subsumir, um outro tempo: aquele em que pela paciência e delicadeza, modelamos e cultivamos a reflexão. Recuperando o encadeamento dos três pontos delimitados anteriormente, isso é entre:

1. "entre-lugar" e sua consequência, um estar-sempre-em-trânsito;

2. uma concepção de cosmopolitismo que cria um terreno de reconhecimento entre diferenças e dissonâncias; e

3. uma configuração em que o processo de interiorização do é exterior e estrangeiro engendra uma potência anônima e singular; acredito que o superastro cumpra o papel de tornar possível o exercício de teorização sobre a performance.

O entendimento dessa realização (apresentada aqui em estado de hipótese) apoia-se sob certa perspectiva acerca da contemporaneidade. 
Gostaria de indicá-la a partir da elaboração proposta por H. Gumbrecht, sem deixar implicado que ela seja a única ou a melhor dentre as tentativas de aproximação do mundo contemporâneo. Seu rendimento é pertinente por mostrar de forma econômica o "palco" em que o superastro dança, em minha hipótese. H. Gumbrecht tratou de explorar a tensão que perpassa o mundo contemporâneo através da tipologia entre "culturas de sentido" e "culturas de presença", advertindo-nos de que uma tipologia não se estabelece e não funciona como uma descrição da realidade. $\mathrm{O}$ autor argumenta que em uma "cultura de sentido" a autorreferencialidade humana está sempre ligada a uma subjetividade ou consciência que se compreende como excêntrica ao mundo a que pertence. Por esse caminho, conhecer o mundo torna-se dotá-lo de sentido. Por sua vez, em uma "cultura de presença", a autorreferência liga-se ao corpo, e o corpo não se entende em separado do mundo. $\mathrm{O}$ corpo está espacial e fisicamente integrado ao mundo que o rodeia. Pelo caminho de uma "cultura de presença", o conhecimento acerca do mundo não resulta do debruçar do sujeito sobre seus "objetos", mas relaciona-se a um desvelamento e/ou revelação (GUMBRECHT, 2010, p. 104 -114).

O superastro, movido pela força ambígua que o pensamento de Silviano Santiago the concede, esgarça os tipos apresentados por Gumbrecht, desempenhando assim sua função teórica e reflexiva. Em uma "cultura de presença", aquela em que os dias se passam como se fosse carnaval, a performance atua simultaneamente como algo que exige espaço e algo que torna possível que essa exigência seja notável. Esse movimento dota os corpos da capacidade de envolverem-se e inscreverem-se nessa temporalidade presente a si mesma (presença). A performance, nesse sentido, é menos uma ação do que uma magia. $\mathrm{O}$ superastro, potência anônima e singular, não entra nesse território para substituir um sujeito autoconsciente e autorreferente e, então, capaz de dotar a magia de sentido, interpretando-a como se fosse uma agência privilegiada do ego. Sempre-em-trânsito, compondo a si como o mesmo que faz ver diferenças e dissonâncias, o superastro põe em relevo a inescapável falibilidade das respostas ao mesmo tempo em que expõe as necessárias, tensas, arredias, fragmentadas e não-exatas questões que surgem no território da performance e que não podem, por ela mesma, serem respondidas.

A função do superastro é evidenciar, expor, comentar as figuras de seu entorno cultural em sua superficialidade. Sem dotá-las de uma 
profundidade existencial, o superastro oferece uma disposição para pensálas e não simplesmente consumi-las ou reproduzi-las. O superastro opera como modelo ou estilo, pode ser seguido, copiado, pode ser imitado sem perder-se. Mas, teoricamente mais decisivo, é o fato de que ele permite um diagnóstico. Um diagnóstico não é uma interpretação, no sentido hermenêutico. É um mapeamento, a descrição de um cenário pelos seus sintomas e índices. A condição de possibilidade desse empreendimento teórico está ligada à abertura, no tempo da presença, de um outro modo temporal: o da paradoxal perene plasticidade que, sendo sempre a mesma, não se fecha em uma singularidade irredutível, inefável. Atuando na região que se forma ao redor do movimento do corpo (voz, letra, dança), a função do superastro é configurar-se como modelo, apresentando a mudança ao tornar-se, incessantemente, espontaneamente, semelhante a si. Esse movimento temporal suplementa (no sentido derridiano) a presença, atuando, encenando, apontando a direção para a significação das obras e do valor das coisas humanas.

Por essa via, certamente a ser melhor pavimentada, o superastro não deve ser compreendido como uma versão intensificada da performance, nem uma caracterização presa ao contexto imediato do qual parte. $\mathrm{O}$ superastro é um empreendimento intelectual que se liga a um contexto mais amplo e profundo, em que atentamos para contínua tensão entre as diferentes esferas de valores que permeiam o mundo contemporâneo. Nesse ambiente agonístico, o operador superastro, fantasioso e artificial, configura um campo de forças em que cada linha se torna, necessariamente, um processo de tradução e de transferência de sentido. Sua dinâmica atua como um ver-direcionado e cumpre a tarefa de mostrar que, para os nossos tempos, nem o sentido reflexivo, nem a presença performática, engendram por si mesmos instrumentos capazes de nortear um entendimento sobre a cultura.

Se há alguma razão no que foi dito aqui, a carreira do superastro ganha um horizonte mais amplo a que eu gostaria de aludir, citando um superastro, um desigual em relação a Caetano. Raul Seixas nos ensina, em “ eu também vou reclamar", música dele e de Paulo Coelho, de 1976: "E sendo nuvem passageira. Não me leva à beira. Disso tudo que eu quero chegar. E fim de papo!” (SEIXAS, COELHO, 1976) 


\section{Referências}

CAVALCANTI, Maria Laura Viveiros de Castro. Drama, Ritual e performance em Victor Turner. Sociol. Antropol. Rio de Janeiro, v. 3, n. 6, p. 411-440, Dec. 2013. Disponível em http://www.scielo.br/scielo. php?script $=$ sci_arttext\&pid=S2238-38752013000600411\&lng=en\&nr $\mathrm{m}=$ iso. Access on 08 Sept. 2019. DOI: http://dx.doi.org/10.1590/2238$38752013 v 363$.

COELHO, Frederico. Eu, brasileiro, confesso minha culpa e meu pecado: cultura marginal no Brasil nas décadas de 1960 e 1970. Rio de Janeiro: Civilização Brasileira, 2010.

DERRIDA, J. Economimesis. Mimesis des articulations. Paris: Ed. Aubier-Flammarion, 1975.

BUENO, André. Pássaro de Fogo no terceiro mundo: o poeta Torquato Neto e sua época. Rio de Janeiro: 7Letras, 2005.

GUMBRECHT, H. U. Produção de presença: o que o sentido não consegue transmitir. Tradução de Soares. Rio de Janeiro: Contraponto; Ed. PUC-Rio, 2010

LACAPRA, Dominick. Rethinking Intellectual History: Texts, Contexts, Language. Ithaca: 1983, p.36-71.

MELLO, J.M. O capitalismo tardio. São Paulo: Brasiliense, 1982.

PINTO, A. M.; VALINHAS, M. L. O. Historicidade, retórica e ficção: interlocuções com a historiografia de Dominick LaCapra. Revista Rhêtorikê, v. 03, p. 1-18, jun. 2010.

ORTIZ, R. A moderna tradição brasileira-cultura brasileira e indústria cultural. São Paulo: Brasiliense, 1988.

SANTIAGO, Silviano. Uma literatura nos trópicos: ensaios sobre dependência cultural. Rio de Janeiro: Rocco, 1978.

SANTIAGO, Silviano. O cosmopolitismo do pobre: crítica literária e crítica cultural. Belo Horizonte: Editora UFMG, 2004. 252 p.

SANTIAGO, Silviano. Ora (direis) puxar conversa! 1. Ed. Belo Horizonte: Editora UFMG, 2006. 
SEIXAS, R. COELHO, P. Eu também vou reclamar. $U M G, 1976$ Disponível em https://www.youtube.com/watch? $\mathrm{v}=\mathrm{a} 0 \mathrm{pHi0jMdOk}$ Acesso em:

SÜSSEKIND, Flora. Coro, contrários, massa: a experiência tropicalista e o Brasil de fins dos anos 60. In: BASSUALDO, Carlos (Org.). Tropicália: uma revolução na cultura brasileira (1967-1972). São Paulo: Cosac Naify, 2007. p. 31-58.

VELOSO, C. Superbacana. Polygram, 1967 (remasterizada 2006). Disponível em https://www.youtube.com/watch?v=K5iIJjRx4rM. Acesso em:

TURNER, Victor; BRUNER, Edward. The anthropology of performance. New York, PAJ Publications, 1987.

TURNER, Victor. On the edge of the bush: Anthropology as experience. Tucson: Arizona University Press, 1985.

ZUMTHOR, P. Performance, recepção, leitura. Tradução: Jerusa Pires Ferreira e Suely Fenerich. São Paulo: UBU, 2018.

Recebido em: 29 de setembro de 2019. Aprovado em: 6 de março de 2020. 